\title{
A Triple Fixed Point Theorem for Multimap in a Hausdorff Fuzzy Metric Space
}

\author{
K. P. R. Rao ${ }^{1}$ and K. R. K. Rao ${ }^{2}$ \\ ${ }^{1}$ Department of Mathematics, Acharya Nagarjuna University, Nagarjuna Nagar 522 510, India \\ ${ }^{2}$ Department of Mathematics, Vignana Bharathi Institute of Technology, Aushapur, Ghatkesar, Hyderabad 501 301, India
}

Correspondence should be addressed to K. P. R. Rao; kprrao2004@yahoo.com

Received 25 September 2012; Revised 30 November 2012; Accepted 5 December 2012

Academic Editor: Pierpaolo D’Urso

Copyright (c) 2013 K. P. R. Rao and K. R. K. Rao. This is an open access article distributed under the Creative Commons Attribution License, which permits unrestricted use, distribution, and reproduction in any medium, provided the original work is properly cited.

We obtain two triple fixed point theorems for a multimap in a Hausdorff fuzzy metric space.

\section{Introduction and Preliminaries}

The concept of fuzzy sets was introduced by Zadeh [1] in 1965 as a mathematical tool to represent vagueness in every day life. Since then, it was developed extensively by many authors, which also include interesting applications of this theory in diverse areas. To use this concept in topology and analysis, several researchers have defined fuzzy metric spaces in several ways (e.g., [2-4]). George and Veeramani [2] have modified the concept of fuzzy metric space introduced by Kramosil and Michálek [3] and also have succeeded in inducing a Hausdroff topology on such fuzzy metric space which is often used in current research these days. Later Grabiec [5] proved the contraction principle in the setting of fuzzy metric spaces introduced in [2]. Fuzzy metric spaces have many applications, for example, the various concepts of fuzzy topology have already been found in vital applications in quantum particle physics particularly in connection with both string and $\epsilon^{(\infty)}$ theory which were studied and formulated by El Naschie [6] and also most recently Gregori et al. [7] have furnished several interesting examples of fuzzy metrics in the sense of George and Veeramani [2] and have also utilized such fuzzy metrics to color image processing. For fixed point theorems in fuzzy metric spaces some of the interesting references are in $[2,5,8-16]$.

The theory of set valued maps has applications in control theory, convex optimization, differential inclusions, and economics. The study of fixed points for multivalued contraction mappings using the Hausdorff metric was initiated by Nadler [17]. In 2004, Rodríguez-López and Romaguera [18] introduced Hausdorff's fuzzy metric on the set of the nonempty compact subsets of a given fuzzy metric space. Later several authors proved some fixed point theorems for multivalued maps in fuzzy metric spaces (e.g., [19-22]). The existence of fixed points for various multivalued contractive mappings has been studied by many authors under different conditions. For details, we refer the reader to $[3,17,23-$ 29] and the references therein. In 2006, Gnana Bhaskar and Lakshmikantham [30] introduced the notion of a coupled fixed point in partially ordered metric spaces, also discussed some problems of the uniqueness of a coupled fixed point, and applied their results to the problems of the existence and uniqueness of a solution for the periodic boundary value problems. In 2011, Samet and Vetro [31] extended the coupled fixed point theorems for a multivalued mapping and later several authors, namely, Hussain and Alotaibi [32], Aydi et al. [33], and Abbas et al. [34] proved coupled coincidence point theorems in partially ordered metric spaces. Borcut [35] observed that the coupled fixed points technique cannot solve a system with the following form: $x^{2}+2 y z-6 x+3=0, y^{2}+$ $2 z x-6 y+3=0, z^{2}+2 x y-6 z+3=0$ and hence Berinde and Borcut [36] introduced the concept of triple fixed points and obtained a tripled fixed point theorem for a single valued map in partially ordered metric spaces. Moreover, these results 
could be used to study the existence of solutions of periodic boundary value problem involving $y^{11}=f\left(t, y, y^{1}\right)$.

In this paper, we obtain a triple fixed point theorem for a multimap in a Hausdorff fuzzy metric space and using it, we obtain a common triple fixed point for a multi- and single valued maps.

In the sequel, we need the following.

Definition 1 (see [37]). A binary operation $*:[0,1] \times[0,1] \rightarrow$ $[0,1]$ is a continuous $t$-norm if it satisfies the following conditions:

(1) $*$ is associative and commutative,

(2) $*$ is continuous,

(3) $a * 1=a$ for all $a \in[0,1]$,

(4) $a * b \leq c * d$ whenever $a \leq c$ and $b \leq d$, for each $a, b, c, d \in[0,1]$.

Two typical examples of continuous $t$-norm are $a * b=a b$ and $a * b=\min \{a, b\}$.

Definition 2 (see [2]). A 3-tuple $(X, M, *)$ is called a fuzzy metric space if $X$ is an arbitrary (nonempty) set, $*$ is a continuous $t$-norm, and $M$ is a fuzzy set on $X^{2} \times(0, \infty)$, satisfying the following conditions for each $x, y, z \in X$ and each $t$ and $s>0$,

(1) $M(x, y, t)>0$,

(2) $M(x, y, t)=1$ if and only if $x=y$,

(3) $M(x, y, t)=M(y, x, t)$,

(4) $M(x, y, t) * M(y, z, s) \leq M(x, z, t+s)$,

(5) $M(x, y, \cdot):(0, \infty) \rightarrow[0,1]$ is continuous.

Let $(X, M, *)$ be a fuzzy metric space. For $t>0$, the open ball $B(x, r, t)$ with centre $x \in X$ and radius $0<r<1$ is defined by $B(x, r, t)=\{y \in X: M(x, y, t)>1-r\}$.

A subset $A \subset X$ is called open if for each $x \in A$, there exist $t>0$ and $0<r<1$ such that $B(x, r, t) \subset A$. Let $\tau$ denote the family of all open subsets of $X$. Then $\tau$ is called the topology on $X$ induced by the fuzzy metric $M$. This topology is Hausdorff and first countable. A subset $A$ of $X$ is said to be F-bounded if there exist $t>0$ and $0<r<1$ such that $M(x, y, t)>1-r$ for all $x, y \in A$.

Grabiec [5] obtained the following important lemma.

Lemma 3 (see [5]). Let $(X, M, *)$ be a fuzzy metric space. Then $M(x, y, t)$ is nondecreasing with respect to $t$, for all $x, y$ in $X$.

Rodríguez-López and Romaguera [18] defined the continuity of fuzzy metric $M$ and obtained the following lemma relating to the continuity of $M$.
Definition 4. Let $(X, M, *)$ be a fuzzy metric space. $M$ is said to be continuous on $X^{2} \times(0, \infty)$ if

$$
\lim _{n \rightarrow \infty} M\left(x_{n}, y_{n}, t_{n}\right)=M(x, y, t),
$$

whenever a sequence $\left\{\left(x_{n}, y_{n}, t_{n}\right)\right\}$ in $X^{2} \times(0, \infty)$ converges to a point $(x, y, t) \in X^{2} \times(0, \infty)$, that is, whenever

$$
\begin{aligned}
& \lim _{n \rightarrow \infty} M\left(x_{n}, x, t\right)=\lim _{n \rightarrow \infty} M\left(y_{n}, y, t\right)=1, \\
& \lim _{n \rightarrow \infty} M\left(x, y, t_{n}\right)=M(x, y, t) .
\end{aligned}
$$

Lemma 5 (see [18]). Let $(X, M, *)$ be a fuzzy metric space. Then $M$ is a continuous function on $X^{2} \times(0, \infty)$.

From now onwards, $(A)$ will denote the following condition:

$$
\lim _{t \rightarrow \infty} M(x, y, t)=1, \quad \forall x, y \in X .
$$

In 1994, Mishra et al. [13] proved the following lemma relating to Cauchy sequences in fuzzy metric spaces.

Lemma 6 (see [13]). Let $\left\{y_{n}\right\}$ be a sequence in fuzzy metric space $(X, M, *)$ satisfying $(A)$. If there exists a positive number $k<1$ such that

$$
M\left(y_{n}, y_{n+1}, k t\right) \geq M\left(y_{n-1}, y_{n}, t\right), \quad t>0, n=1,2, \ldots,
$$

then $\left\{y_{n}\right\}$ is a Cauchy sequence in $X$.

Definition 7 ([18], Definition 2.2). Let $B$ be a nonempty subset of a fuzzy metric space $(X, M, *)$. For $a \in X$ and $t>0$, define $M(a, B, t)=\sup \{M(a, b, t) / b \in B\}$.

Throughout the paper, let $K(X)$ denote the class of all nonempty compact subsets of $X$.

Lemma 8 ([18], Lemma 1). Let $(X, M, *)$ be a fuzzy metric space. Then for each $a \in X, B \in K(X)$ and $t>0$, there exists $b \in B$ such that $M(a, B, t)=M(a, b, t)$.

Definition 9 (see [18]). Let $(X, M, *)$ be a fuzzy metric space. For each $A, B \in K(X)$ and $t>0$, set

$$
H_{M}(A, B, t)=\min \left\{\inf _{x \in A} M(x, B, t), \inf _{y \in B} M(A, y, t)\right\} .
$$

The 3-tuple $\left(K(X), H_{M}, *\right)$ is called a Hausdorff fuzzy metric space.

We use the following lemma proved by Haghi et al. [38] in Theorem 15 in Section 2.

Lemma 10 (see [38]). Let $X$ be a nonempty set and $g: X \rightarrow$ $X$ be a mapping. Then there exists a subset $E \subseteq X$ such that $g(E)=g(X)$ and $g: E \rightarrow X$ is one one.

Now, we give the following definitions for a hybrid pair of mappings (see also [39]). 
Definition 11. Let $X$ be a nonempty set, $T: X \times X \times X \rightarrow$ $2^{X}$ (collection of all nonempty subsets of $X$ ) and $f: X \rightarrow X$.

(i) The point $(x, y, z) \in X \times X \times X$ is called a tripled fixed of $T$ if

$$
\begin{aligned}
& x \in T(x, y, z), \\
& y \in T(y, x, y), \\
& z \in T(z, y, x) .
\end{aligned}
$$

(ii) The point $(x, y, z) \in X \times X \times X$ is called a tripled coincident point of $T$ and $f$ if

$$
\begin{aligned}
& f x \in T(x, y, z), \\
& f y \in T(y, x, y), \\
& f z \in T(z, y, x) .
\end{aligned}
$$

(iii) The point $(x, y, z) \in X \times X \times X$ is called a tripled common fixed point of $T$ and $f$ if

$$
\begin{aligned}
& x=f x \in T(x, y, z), \\
& y=f y \in T(y, x, y), \\
& z=f z \in T(z, y, x) .
\end{aligned}
$$

Definition 12. Let T: $X \times X \times X \rightarrow 2^{X}$ be a multivalued map and $f$ be a self-map on $X$. The Hybrid pair $\{T, f\}$ is called $w$-compatible if $f(T(x, y, z)) \subseteq T(f x, f y, f z)$ whenever $(x, y, z)$ is a tripled coincidence point of $T$ and $f$.

\section{Main Result}

First we prove a slightly different result from Lemma 6 which is essential in proving our main result.

Lemma 13. Let $\left\{x_{n}\right\},\left\{y_{n}\right\}$, and $\left\{z_{n}\right\}$ be sequences in fuzzy metric space $(X, M, *)$ satisfying $(A)$. If there exists a positive number $k<1$ such that

$$
\begin{aligned}
& \min \left\{M\left(x_{n}, x_{n+1}, k t\right), M\left(y_{n}, y_{n+1}, k t\right), M\left(z_{n}, z_{n+1}, k t\right)\right\} \\
& \geq \min \left\{M\left(x_{n-1}, x_{n}, t\right), M\left(y_{n-1}, y_{n}, t\right), M\left(z_{n-1}, z_{n}, t\right)\right\},
\end{aligned}
$$

for all $t>0, n=1,2, \ldots$, then $\left\{x_{n}\right\},\left\{y_{n}\right\}$ and $\left\{z_{n}\right\}$ are Cauchy sequences in $X$.
Proof. We have

$$
\begin{aligned}
& \min \left\{M\left(x_{n}, x_{n+1}, k t\right),\right. \\
& \left.M\left(y_{n}, y_{n+1}, k t\right), M\left(z_{n}, z_{n+1}, k t\right)\right\} \\
& \geq \min \left\{M\left(x_{n-1}, x_{n}, t\right),\right. \\
& \\
& \left.M\left(y_{n-1}, y_{n}, t\right), M\left(z_{n-1}, z_{n}, t\right)\right\} \\
& \geq \min \left\{M\left(x_{n-2}, x_{n-1}, \frac{t}{k^{2}}\right),\right. \\
& \left.M\left(y_{n-2}, y_{n-1}, \frac{t}{k^{2}}\right), M\left(z_{n-2}, z_{n-1}, \frac{t}{k^{2}}\right)\right\} \\
& \geq \min \left\{M\left(x_{0}, x_{1}, \frac{t}{k^{n}}\right), M\left(y_{0}, y_{1}, \frac{t}{k^{n}}\right),\right. \\
& \left.M\left(z_{0}, z_{1}, \frac{t}{k^{n}}\right)\right\} .
\end{aligned}
$$

Hence,

$$
\begin{gathered}
M\left(x_{n}, x_{n+1}, t\right) \\
\geq \min \left\{M\left(x_{0}, x_{1}, \frac{t}{k^{n}}\right), M\left(y_{0}, y_{1}, \frac{t}{k^{n}}\right),\right. \\
\left.M\left(z_{0}, z_{1}, \frac{t}{k^{n}}\right)\right\} .
\end{gathered}
$$

Now, for any positive integer $p$,

$$
\begin{aligned}
& M\left(x_{n}, x_{n+p}, t\right) \\
& \geq M\left(x_{n}, x_{n+1}, \frac{t}{p}\right) * M\left(x_{n+1}, x_{n+2}, \frac{t}{p}\right) \\
& * \cdots * M\left(x_{n+p-1}, x_{n+p}, \frac{t}{p}\right) \\
& \geq \min \left\{M\left(x_{0}, x_{1}, \frac{t}{p k^{n}}\right),\right. \\
& \left.\quad M\left(y_{0}, y_{1}, \frac{t}{p k^{n}}\right), M\left(z_{0}, z_{1}, \frac{t}{p k^{n}}\right)\right\} \\
& * \min \left\{M\left(x_{0}, x_{1}, \frac{t}{p k^{n+1}}\right),\right. \\
& \left.M\left(y_{0}, y_{1}, \frac{t}{p k^{n+1}}\right), M\left(z_{0}, z_{1}, \frac{t}{p k^{n+1}}\right)\right\}
\end{aligned}
$$




$$
\begin{array}{r}
* \cdots * \min \left\{M\left(x_{0}, x_{1}, \frac{t}{p k^{n+p-1}}\right),\right. \\
M\left(y_{0}, y_{1}, \frac{t}{p k^{n+p-1}}\right), \\
\left.M\left(z_{0}, z_{1}, \frac{t}{p k^{n+p-1}}\right)\right\} .
\end{array}
$$

Letting $n \rightarrow \infty$ and using $(A)$, we have

$$
\begin{gathered}
\lim _{n \rightarrow \infty} M\left(x_{n}, x_{n+p}, t\right) \geq 1 * 1 * \cdots * 1=1 . \\
\text { Hence, } \lim _{n \rightarrow \infty} M\left(x_{n}, x_{n+p}, t\right)=1 .
\end{gathered}
$$

Thus $\left\{x_{n}\right\}$ is a Cauchy sequence in $X$. Similarly, we can show that $\left\{y_{n}\right\}$ and $\left\{z_{n}\right\}$ are also Cauchy sequences in $X$.

Now, we are ready to prove our first main result.

Theorem 14. Let $(X, M, *)$ be a complete fuzzy metric space satisfying condition $(A)$ and $F: X \times X \times X \rightarrow \mathscr{K}(X)$ be a set valued mapping satisfying

$$
\begin{aligned}
H_{M} & (F(x, y, z), F(u, v, w), k t) \\
& \geq \min \{M(x, u, t), M(y, v, t), M(z, w, t)\}
\end{aligned}
$$

for each $x, y, z, u, v, w \in X, t>0$, where $0<k<1$.

Then $F$ has a tripled fixed point.

Proof. Let $x_{0}, y_{0}, z_{0} \in X$.

Choose $x_{1} \in F\left(x_{0}, y_{0}, z_{0}\right), y_{1} \in F\left(y_{0}, x_{0}, y_{0}\right), z_{1} \in$ $F\left(z_{0}, y_{0}, x_{0}\right)$.

Since $F$ is compact valued, by Lemma 8 , there exists $x_{2} \in$ $F\left(x_{1}, y_{1}, z_{1}\right)$ such that

$$
\begin{aligned}
M & \left(x_{1}, x_{2}, k t\right) \\
& =\sup _{x \in F\left(x_{1}, y_{1}, z_{1}\right)} M\left(x_{1}, x, k t\right) \\
& \geq H_{M}\left(F\left(x_{0}, y_{0}, z_{0}\right), F\left(x_{1}, y_{1}, z_{1}\right), k t\right) \\
& \geq \min \left\{M\left(x_{0}, x_{1}, t\right), M\left(y_{0}, y_{1}, t\right), M\left(z_{0}, z_{1}, t\right)\right\} .
\end{aligned}
$$

Since $F$ is compact valued, by Lemma 8 , there exists $y_{2} \in$ $F\left(y_{1}, x_{1}, y_{1}\right)$ such that

$$
\begin{aligned}
M & \left(y_{1}, y_{2}, k t\right) \\
& =\sup _{y \in F\left(y_{1}, x_{1}, y_{1}\right)} M\left(y_{1}, y, k t\right) \\
& \geq H_{M}\left(F\left(y_{0}, x_{0}, y_{0}\right), F\left(y_{1}, x_{1}, y_{1}\right), k t\right) \\
& \geq \min \left\{M\left(y_{0}, y_{1}, t\right), M\left(x_{0}, x_{1}, t\right), M\left(y_{0}, y_{1}, t\right)\right\} \\
& \geq \min \left\{M\left(x_{0}, x_{1}, t\right), M\left(y_{0}, y_{1}, t\right), M\left(z_{0}, z_{1}, t\right)\right\} .
\end{aligned}
$$

Since $F$ is compact valued, by Lemma 8 , there exists $z_{2} \in$ $F\left(z_{1}, y_{1}, x_{1}\right)$ such that

$$
\begin{aligned}
M & \left(z_{1}, z_{2}, k t\right) \\
& =\sup _{z \in F\left(z_{1}, y_{1}, x_{1}\right)} M\left(z_{1}, z, k t\right) \\
& \geq H_{M}\left(F\left(z_{0}, y_{0}, x_{0}\right), F\left(z_{1}, y_{1}, x_{1}\right), k t\right) \\
& \geq \min \left\{M\left(z_{0}, z_{1}, t\right), M\left(y_{0}, y_{1}, t\right), M\left(x_{0}, x_{1}, t\right)\right\} \\
& =\min \left\{M\left(x_{0}, x_{1}, t\right), M\left(z_{0}, z_{1}, t\right), M\left(y_{0}, y_{1}, t\right)\right\} .
\end{aligned}
$$

Thus,

$$
\begin{aligned}
& \min \left\{M\left(x_{1}, x_{2}, k t\right), M\left(y_{1}, y_{2}, k t\right), M\left(z_{1}, z_{2}, k t\right)\right\} \\
& \geq \min \left\{M\left(x_{0}, x_{1}, t\right), M\left(y_{0}, y_{1}, t\right), M\left(z_{0}, z_{1}, t\right)\right\} .
\end{aligned}
$$

Continuing in this way, we can obtain sequences $\left\{x_{n}\right\},\left\{y_{n}\right\}$ and $\left\{z_{n}\right\}$ in $X$ such that $x_{n+1} \in F\left(x_{n}, y_{n}, z_{n}\right), y_{n+1} \in$ $F\left(y_{n}, x_{n}, y_{n}\right)$ and $z_{n+1} \in F\left(z_{n}, y_{n}, x_{n}\right)$ such that

$$
\begin{aligned}
& \min \left\{M\left(x_{n}, x_{n+1}, k t\right) M\left(y_{n}, y_{n+1}, k t\right) M\left(z_{n}, z_{n+1}, k t\right)\right\} \\
& \geq \min \left\{M\left(x_{n-1}, x_{n}, t\right), M\left(y_{n-1}, y_{n}, t\right), M\left(z_{n-1}, z_{n}, t\right)\right\} .
\end{aligned}
$$

Hence, by Lemma $13,\left\{x_{n}\right\}\left\{y_{n}\right\}$ and $\left\{z_{n}\right\}$ are Cauchy sequences in $X$.

Since $X$ is complete, there exist $x, y, z \in X$ such that $\lim _{n \rightarrow \infty}\left\{x_{n}\right\}=x, \lim _{n \rightarrow \infty}\left\{y_{n}\right\}=y$ and $\lim _{n \rightarrow \infty}\left\{z_{n}\right\}=$ $z$. Consider

$$
\begin{aligned}
& H_{M}\left(F\left(x_{n}, y_{n}, z_{n}\right), F(x, y, z), k t\right) \\
& \quad \geq \min \left\{M\left(x_{n}, x, t\right), M\left(y_{n}, y, t\right), M\left(z_{n}, z, t\right)\right\} .
\end{aligned}
$$

Letting $n \rightarrow \infty$, we get

$$
\begin{aligned}
& \lim _{n \rightarrow \infty} H_{M}\left(F\left(x_{n}, y_{n}, z_{n}\right), F(x, y, z), k t\right)=1 \text { so that } \\
& \lim _{n \rightarrow \infty} H_{M}\left(F\left(x_{n}, y_{n}, z_{n}\right), F(x, y, z), t\right)=1 .
\end{aligned}
$$

Similarly, we can show that

$$
\begin{aligned}
& \lim _{n \rightarrow \infty} H_{M}\left(F\left(y_{n}, x_{n}, y_{n}\right), F(y, x, y), t\right)=1, \\
& \lim _{n \rightarrow \infty} H_{M}\left(F\left(z_{n}, y_{n}, x_{n}\right), F(z, y, x), t\right)=1 .
\end{aligned}
$$

Since $x_{n+1} \in F\left(x_{n}, y_{n}, z_{n}\right), y_{n+1} \in F\left(y_{n}, x_{n}, y_{n}\right)$, and $z_{n+1} \in$ $F\left(z_{n}, y_{n}, x_{n}\right)$, from (20) and (21), we have

$$
\begin{aligned}
& \lim _{n \rightarrow \infty} \sup _{a \in F(x, y, z)} M\left(x_{n+1}, a, t\right)=1, \\
& \lim _{n \rightarrow \infty} \sup _{b \in F(y, x, y)} M\left(y_{n+1}, b, t\right)=1, \\
& \lim _{n \rightarrow \infty} \sup _{c \in F(z, y, x)} M\left(z_{n+1}, c, t\right)=1 .
\end{aligned}
$$


Hence there exist sequences $p_{n} \in F(x, y, z), q_{n} \in F(y, x, y)$ and $r_{n} \in F(z, y, x)$ such that

$$
\begin{aligned}
& \lim _{n \rightarrow \infty} M\left(x_{n+1}, p_{n}, t\right)=1, \\
& \lim _{n \rightarrow \infty} M\left(y_{n+1}, q_{n}, t\right)=1, \\
& \lim _{n \rightarrow \infty} M\left(z_{n+1}, r_{n}, t\right)=1, \\
& \text { for each } t>0 .
\end{aligned}
$$

Now, for each $n \in \mathcal{N}$, we have

$$
M\left(p_{n}, x, t\right) \geq M\left(p_{n}, x_{n+1}, \frac{t}{2}\right) * M\left(x_{n+1}, x, \frac{t}{2}\right) .
$$

Letting $n \rightarrow \infty$, we obtain

$$
\lim _{n \rightarrow \infty} M\left(p_{n}, x, t\right)=1 \quad \text { so that } \lim _{n \rightarrow \infty} p_{n}=x .
$$

Similarly, we can show that

$$
\lim _{n \rightarrow \infty} q_{n}=y, \quad \lim _{n \rightarrow \infty} r_{n}=z .
$$

Since $F(x, y, z), F(y, x, y)$, and $F(z, y, x)$ are compact, we have $x \in F(x, y, z), y \in F(y, x, y)$, and $z \in F(z, y, x)$.

Thus, $(x, y, z)$ is a tripled fixed point of $F$.

Using the above theorem, we now prove a tripled coincidence and common fixed point theorem for a hybrid pair of multivalued and single-valued mapping.

Theorem 15. Let $(X, M, *)$ be a complete fuzzy metric space satisfying condition $(A)$ and $F: X \times X \times X \rightarrow \mathscr{K}(X)$ and $g: X \rightarrow X$ be a mappings satisfying

$$
\begin{aligned}
& H_{M}(F(x, y, z), F(u, v, w), k t) \\
& \quad \geq \min \{M(g x, g u, t), M(g y, g v, t), M(g z, g w, t)\},
\end{aligned}
$$

for all $x, y, z, u, v, w \in X, t>0$ and $0<k<1$. Further assume that $F(X \times X \times X) \subseteq g(X)$, then $F$ and $g$ have a tripled coincidence point. Moreover, $F$ and $g$ have a tripled common fixed point if one of the following conditions holds.

(a) The pair $(F, g)$ is $w$-compatible and there exist $\alpha, \beta, \gamma \in$ $X$ such that $\lim _{n \rightarrow \infty} g^{n} x=\alpha, \lim _{n \rightarrow \infty} g^{n} y=\beta$, and $\lim _{n \rightarrow \infty} g^{n} z=\gamma$, whenever $(x, y, z)$ is a tripled coincidence point of $F$ and $g$ and $g$ is continuous at $\alpha, \beta, \gamma$.

(b) There exist $\alpha, \beta, \gamma \in X$ such that $\lim _{n \rightarrow \infty} g^{n} \alpha=x$, $\lim _{n \rightarrow \infty} g^{n} \beta=y$ and $\lim _{n \rightarrow \infty} g^{n} \gamma=z$, whenever $(x, y, z)$ is a tripled coincidence point of $F$ and $g$ and $g$ is continuous at $x, y, z$.

Proof. By Lemma 10, There exists $E \subseteq X$ such that $g: E \rightarrow$ $X$ is one to one and $g(E)=g(X)$.

Now, define $G: g(E) \times g(E) \times g(E) \rightarrow \mathscr{K}(X)$ by $G(g x$, $g y, g z)=F(x, y, z)$ for all $g x, g y, g z \in g(E)$. Since $g$ is oneone on $E, G$ is well defined.
Now,

$$
\begin{aligned}
& H_{M}(G(g x, g y, g z), G(g u, g v, g w), k t) \\
& \quad=H_{M}(F(x, y, z), F(u, v, w), k t) \\
& \quad \geq \min \{M(g x, g u, t), M(g y, g v, t), M(g z, g w, t)\} .
\end{aligned}
$$

Hence $G$ satisfies (13) and all the conditions of Theorem 14.

By Theorem 14, $G$ has a tripled fixed point $(u, v, w) \in$ $g(E) \times g(E) \times g(E)$. Thus,

$$
\begin{aligned}
& u \in G(u, v, w), \\
& v \in G(v, u, v), \\
& w \in G(w, v, u) .
\end{aligned}
$$

Since $F(X \times X \times X) \subseteq g(X)$, there exist $u, v, w \in X \times X \times X$ such that $g u_{1}=u, g v_{1}=v$, and $g w_{1}=w$. So from (29), we have

$$
\begin{aligned}
g u_{1} & \in G\left(g u_{1}, g v_{1}, g w_{1}\right) \\
& =F\left(u_{1}, v_{1}, w_{1}\right), \\
g v_{1} & \in G\left(g v_{1}, g u_{1}, g v_{1}\right) \\
& =F\left(v_{1}, u_{1}, v_{1}\right), \\
g w_{1} & \in G\left(g w_{1}, g v_{1}, g u_{1}\right) \\
& =F\left(w_{1}, v_{1}, u_{1}\right) .
\end{aligned}
$$

This implies that $\left(u_{1}, v_{1}, w_{1}\right) \in X \times X \times X$ is a tripled coincidence point of $F$ and $g$.

Now, following as in [39] except from the inequalities satisfied by $M$ we can show that $F$ and $g$ have a tripled common fixed point.

\section{Acknowledgment}

The authors are thankful to the referee for his valuable suggestions.

\section{References}

[1] L. A. Zadeh, "Fuzzy sets," Information and Control, vol. 8, no. 3, pp. 338-353, 1965.

[2] A. George and P. Veeramani, "On some results in fuzzy metric spaces," Fuzzy Sets and Systems, vol. 64, no. 3, pp. 395-399, 1994.

[3] I. Kramosil and J. Michálek, "Fuzzy metrics and statistical metric spaces," Kybernetika, vol. 11, no. 5, pp. 336-344, 1975.

[4] Z. Deng, "Fuzzy pseudometric spaces," Journal of Mathematical Analysis and Applications, vol. 86, no. 1, pp. 74-95, 1982.

[5] M. Grabiec, "Fixed points in fuzzy metric spaces," Fuzzy Sets and Systems, vol. 27, no. 3, pp. 385-389, 1988.

[6] M. S. El Naschie, "A review of E infinity theory and the mass spectrum of high energy particle physics," Chaos, Solitons and Fractals, vol. 19, no. 1, pp. 209-236, 2004. 
[7] V. Gregori, S. Morillas, and A. Sapena, "Examples of fuzzy metrics and applications," Fuzzy Sets and Systems, vol. 170, pp. 95111, 2011.

[8] B. Singh and M. S. Chauhan, "Common fixed points of compatible maps in fuzzy metric spaces," Fuzzy Sets and Systems, vol. 115, no. 3, pp. 471-475, 2000.

[9] B. Singh and S. Jain, "Semicompatibility and fixed point theorems in fuzzy metric space using implicit relation," International Journal of Mathematics and Mathematical Sciences, no. 16, pp. 2617-2629, 2005.

[10] B. Singh and S. Jain, "Semi compatibility, compatibility and fixed point theorems in fuzzy metric space," Journal of the Chungcheong Mathematical Society, vol. 18, no. 1, pp. 1-22, 2005.

[11] R. Chugh and S. Kumar, "Common fixed point theorem in fuzzy metric spaces," Bulletin of the Calcutta Mathematical Society, vol. 94, no. 1, pp. 17-22, 2002.

[12] R. Vasuki, "Common fixed points for $R$-weakly commuting maps in fuzzy metric spaces," Indian Journal of Pure and Applied Mathematics, vol. 30, no. 4, pp. 419-423, 1999.

[13] S. N. Mishra, N. Sharma, and S. L. Singh, "Common fixed points of maps on fuzzy metric spaces," International Journal of Mathematics and Mathematical Sciences, vol. 17, no. 2, pp. 253-258, 1994.

[14] S. Sharma, "Common fixed point theorems in fuzzy metric spaces," Fuzzy Sets and Systems, vol. 127, no. 3, pp. 345-352, 2002.

[15] Y. J. Cho, "Fixed points in fuzzy metric spaces," Journal of Fuzzy Mathematics, vol. 5, no. 4, pp. 949-962, 1997.

[16] Y. J. Cho, H. K. Pathak, S. M. Kang, and J. S. Jung, "Common fixed points of compatible maps of type $\beta$ on fuzzy metric spaces," Fuzzy Sets and Systems, vol. 93, no. 1, pp. 99-111, 1998.

[17] S. B. Nadler, Jr., "Multi-valued contraction mappings," Pacific Journal of Mathematics, vol. 30, pp. 475-488, 1969.

[18] J. Rodríguez-López and S. Romaguera, "The Hausdorff fuzzy metric on compact sets," Fuzzy Sets and Systems, vol. 147, no. 2, pp. 273-283, 2004.

[19] F. Kiany and A. Amini-Harandi, "Fixed point and endpoint theorems for set-valued fuzzy contraction maps in fuzzy metric spaces," Fixed Point Theory and Applications, vol. 2011, article 94, 9 pages, 2011.

[20] M. Alamgir Khan, "Sumitra,Common fixed point theorems for converse commuting and OWC maps in, fuzzy metric spaces," Punjab University Journal of Mathematics, vol. 44, pp. 57-63, 2012.

[21] P. Vijayaraju and Z. M. I. Sajath, "Common fixed points of single and multivalued maps in fuzzy metric spaces," Applied Mathematics, vol. 2, no. 5, pp. 595-599, 2011.

[22] S. Sedghi, K. P. R. Rao, and N. Shobe, "A general common fixed point theorem for multi-maps satisfying an implicit relation on fuzzy metric spaces," Filomat, vol. 22, no. 1, pp. 1-11, 2008.

[23] A. Beitollahi and P. Azhdari, "Multi-valued contraction theorems in probabilistic metric space," International Journal of Mathematical Analysis, vol. 3, no. 21-24, pp. 1169-1175, 2009.

[24] B. E. Rhoades, "A fixed point theorem for a multivalued nonself-mapping," Commentationes Mathematicae Universitatis Carolinae, vol. 37, no. 2, pp. 401-404, 1996.

[25] Lj. B. Ćirić and J. S. Ume, "Common fixed point theorems for multi-valued non-self mappings," Publicationes Mathematicae Debrecen, vol. 60, no. 3-4, pp. 359-371, 2002.

[26] L. Ćirić, "Fixed point theorems for multi-valued contractions in complete metric spaces," Journal of Mathematical Analysis and Applications, vol. 348, no. 1, pp. 499-507, 2008.
[27] L. Ćirić, "Multi-valued nonlinear contraction mappings," Nonlinear Analysis. Theory, Methods \& Applications A, vol. 71, no. 7-8, pp. 2716-2723, 2009.

[28] N. Mizoguchi and W. Takahashi, "Fixed point theorems for multivalued mappings on complete metric spaces," Journal of Mathematical Analysis and Applications, vol. 141, no. 1, pp. 177188, 1989.

[29] O. Hadžić and E. Pap, "A fixed point theorem for multivalued mappings in probabilistic metric spaces and an application in fuzzy metric spaces," Fuzzy Sets and Systems, vol. 127, no. 3, pp. 333-344, 2002.

[30] T. Gnana Bhaskar and V. Lakshmikantham, "Fixed point theorems in partially ordered metric spaces and applications," Nonlinear Analysis. Theory, Methods \& Applications A, vol. 65, no. 7, pp. 1379-1393, 2006.

[31] B. Samet and C. Vetro, "Coupled fixed point theorems for multivalued nonlinear contraction mappings in partially ordered metric spaces," Nonlinear Analysis. Theory, Methods \& Applications A, vol. 74, no. 12, pp. 4260-4268, 2011.

[32] N. Hussain and A. Alotaibi, "Coupled coincidences for multivalued contractions in partially ordered metric spaces," Fixed Point Theory and Applications, vol. 2011, article 82, 15 pages, 2011.

[33] H. Aydi, M. Abbas, and M. Postolache, "Coupled coincidence points for hybrid pair of mappings via mixed monotone property," Journal of Advanced Mathematical Studies, vol. 5, no. 1, pp. 118-126, 2012.

[34] M. Abbas, L. Ćirić, B. Damjanovi, and M. Ali Khan, "Coupled coincidence and common fixed point theorems for hybrid pair of mappings," Fixed Point Theory and Applications, vol. 2012, article 4, 11 pages, 2012.

[35] M. Borcut, Tripled fixed points for operators in partially ordered metric spaces [Ph.D. thesis], Technical University of ClujNapoca, North Universitari Center from Baia Mare, Faculty of Sciences, 2012

[36] V. Berinde and M. Borcut, "Tripled fixed point theorems for contractive type mappings in partially ordered metric spaces," Nonlinear Analysis. Theory, Methods \& Applications A, vol. 74, no. 15 , pp. 4889-4897, 2011.

[37] B. Schweizer and A. Sklar, "Statistical metric spaces," Pacific Journal of Mathematics, vol. 10, pp. 313-334, 1960.

[38] R. H. Haghi, Sh. Rezapour, and N. Shahzad, "Some fixed point generalizations are not real generalizations," Nonlinear Analysis. Theory, Methods \& Applications A, vol. 74, no. 5, pp. 1799-1803, 2011.

[39] K. P. R. Rao, G. N. V. Kishore, and K. Tas, "A unique common tripled fixed point theorem for hybrid pair of maps," Abstract and Applied Analysis, vol. 2012, Article ID 750403, 9 pages, 2012. 


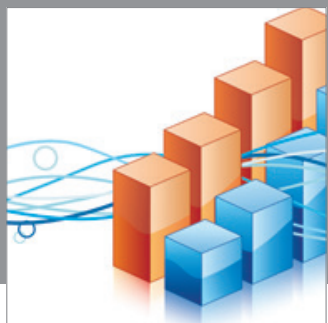

Advances in

Operations Research

mansans

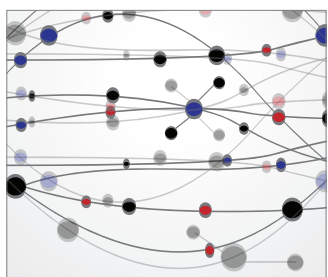

The Scientific World Journal
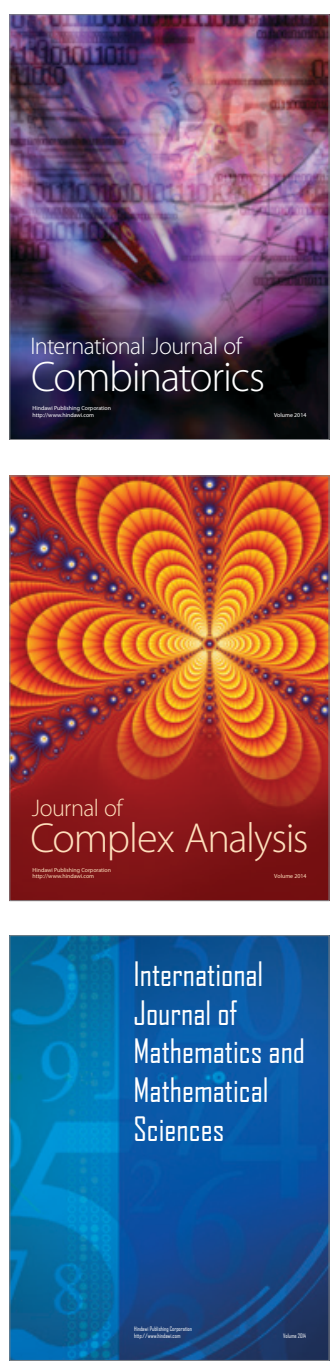
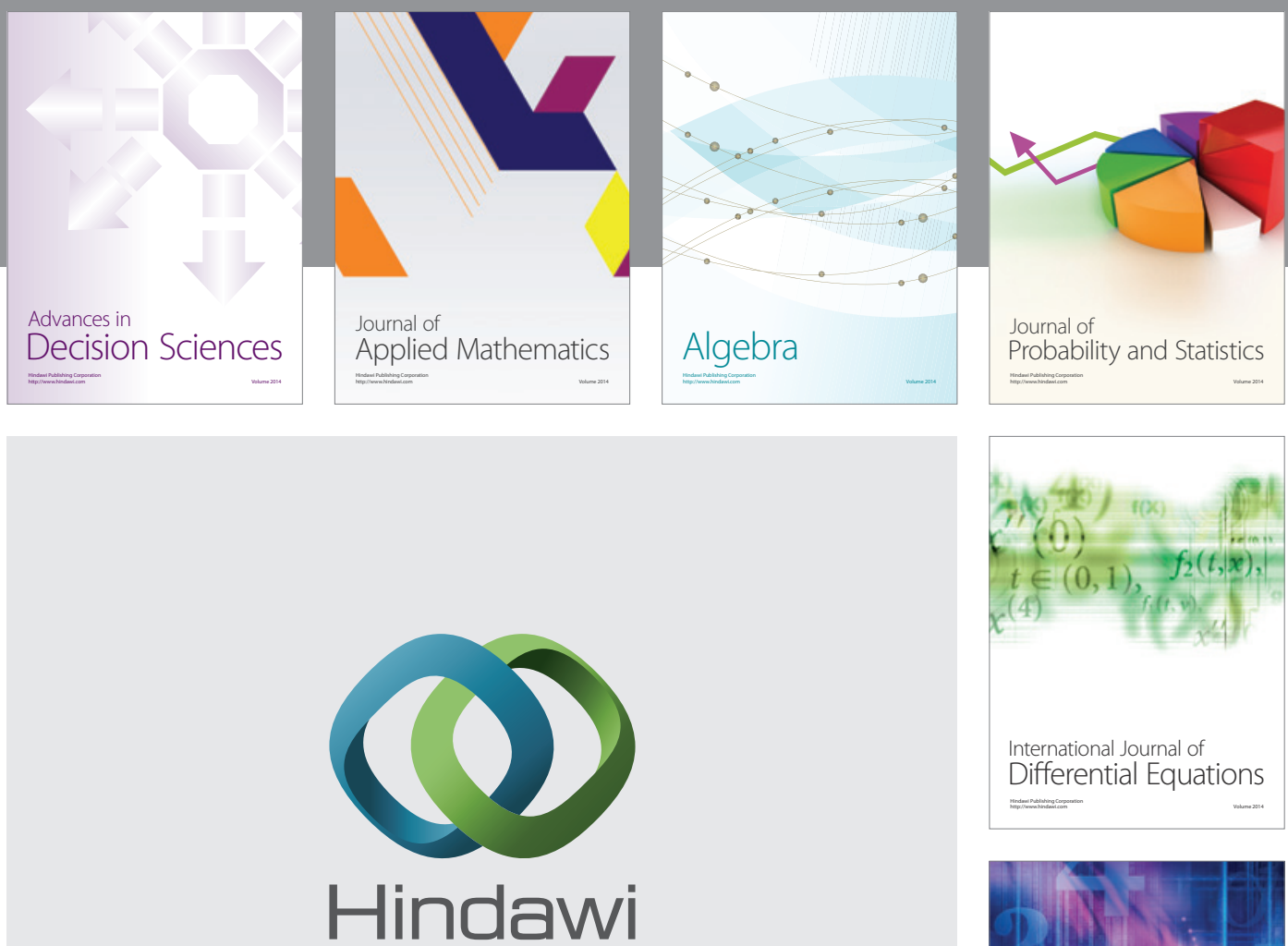

Submit your manuscripts at http://www.hindawi.com
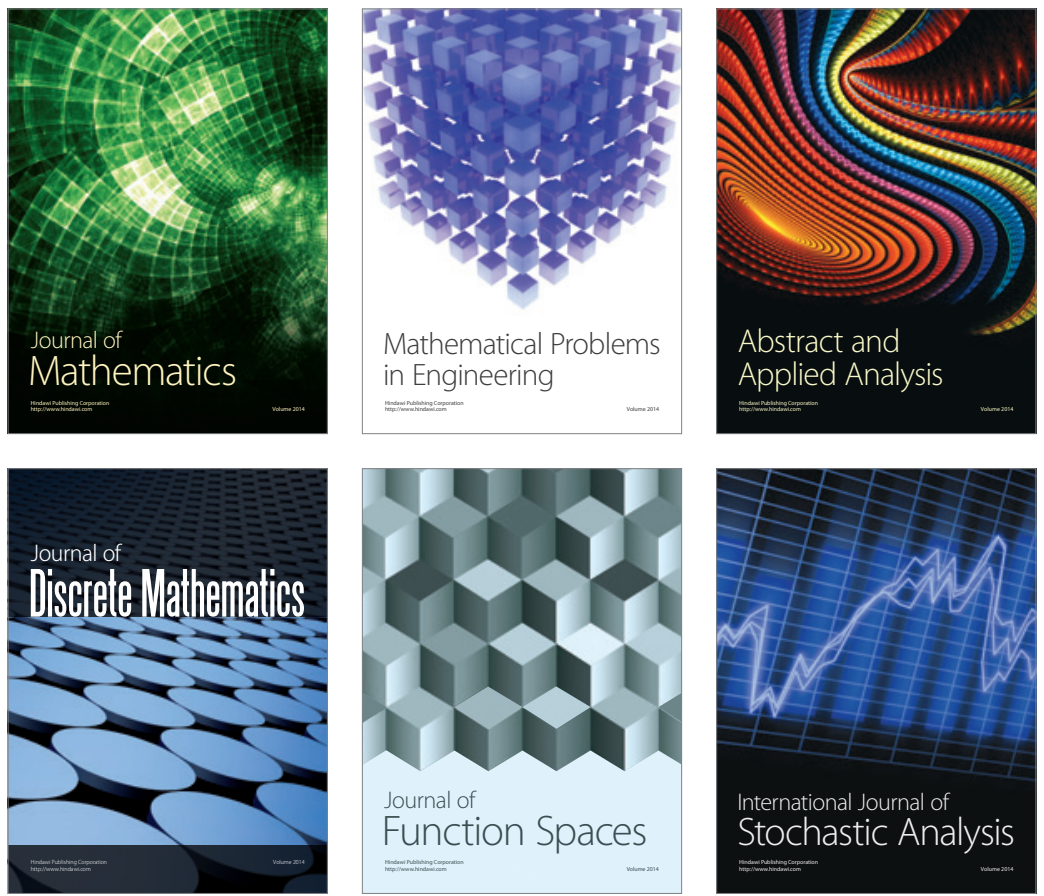

Journal of

Function Spaces

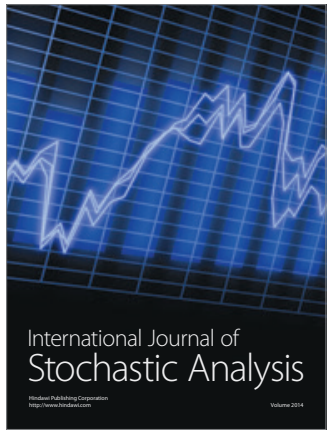

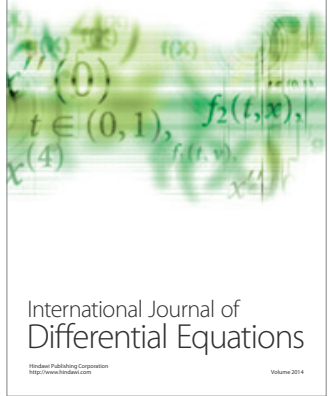
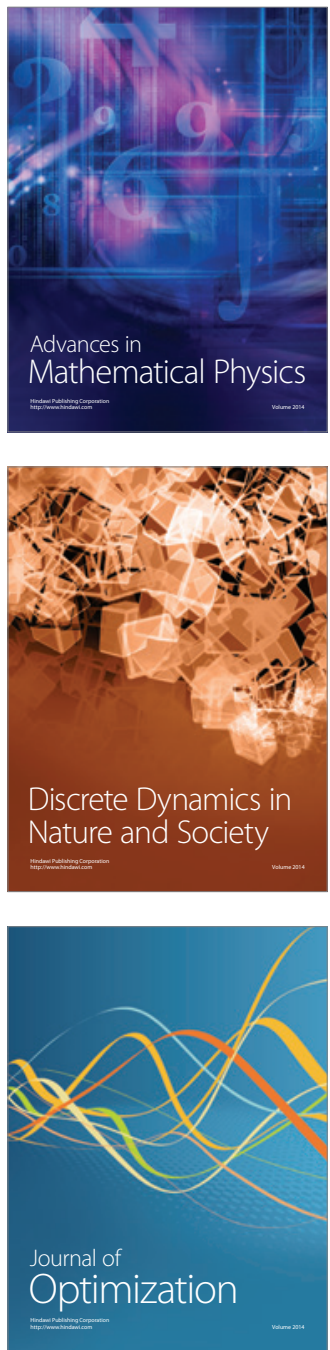